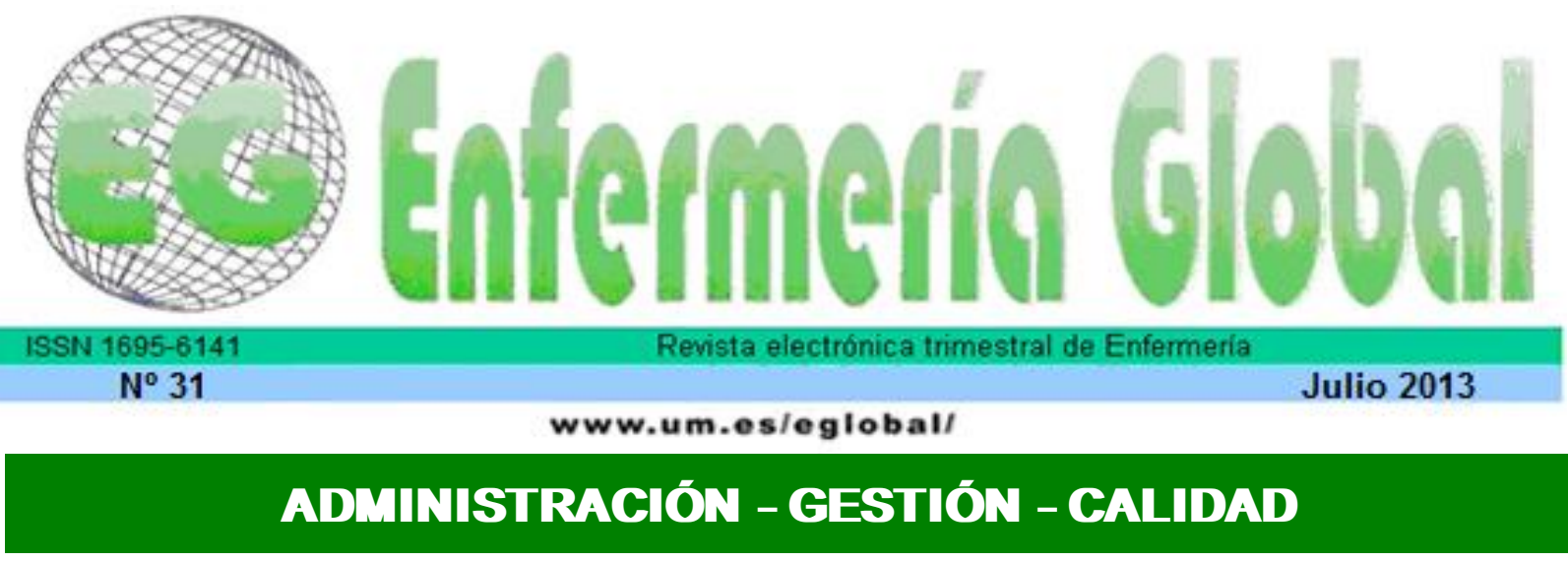

\title{
Carros de emergencia: disponibilidad de los artículos esenciales en un hospital de urgencia norteriograndense
}

Carros de emergência: disponibilidade dos itens essenciais em um hospital de urgência norteriograndense

Car emergency: availability of essential items in a hospital emergency norteriograndense

\section{${ }^{*}$ Da Silva, Hilderjane C ${ }^{* *}$ Da Silva, Alanny KM ${ }^{* * *}$ Dantas, Rodrigo AN *Pessoa, Renata L ****Menezes, Rejane MP}

*Mestranda del Programa de Pos-Graduación en Enfermería. E-mail: hilderjanecarla@hotmal.com

**Discente del Curso de Graduación en Enfermería. ***Enfemero, profesor del Departamento de Enfermería. **** Profesora $\mathrm{Dr}^{\mathrm{a}}$ del Curso de Graduación y Pos-Graduación en Enfermería. Universidad Federal de Rio Grande do Norte (UFRN), Natal, RN, Brasil..

Palabras clave: Parada cardiorrespiratoria; urgencia; emergencia; enfermería

Palavras chave: Parada cardiorrespiratória; urgência; emergência; enfermagem

Keywords: Cardiopulmonary arrest; Urgency; Emergency; Nursing.

\section{RESUMEN}

Se trata de una investigación descriptiva, exploratoria y cuantitativa con el objetivo de evaluar, bajo los patrones de la Sociedad Brasileña de Cardiología (SBC), la disponibilidad de los artículos de nivel I de los Carros de Emergencia (CE) del mayor hospital de urgencia de Rio Grande do Norte. Los datos fueron colectados durante el mes de noviembre de 2010, estando compuesta la muestra por 12 CE. Todos los CE analizados presentaron fallos en la disponibilidad de artículos esenciales, estando las mayores deficiencias relacionadas con los materiales destinados al acceso vascular, control circulatorio y medicamentos dirigidos al tratamiento de las causas de PCR. Se percibe que la falta de recursos humanos y materiales en la institución, así como de un protocolo, dificulta la rutina de comprobación del CE, tarea atribuída al enfermero.

\section{RESUMO}

Trata-se de uma pesquisa descritiva, exploratória e quantitativa com o objetivo de avaliar, sob os padrões da Sociedade Brasileira de Cardiologia (SBC), a disponibilidade dos itens de nível I dos Carros de Emergência (CE) do maior hospital de urgência do Rio Grande do Norte. Os dados foram coletados durante o mês de novembro de 2010, sendo a amostra composta por 12 CE. Todos os CE analisados apresentaram falhas na disponibilidade de itens essenciais, estando as maiores deficiências relacionadas aos materiais destinados ao acesso vascular, controle circulatório e medicamentos voltados ao tratamento das causas de PCR. Percebeu-se que a falta de recursos humanos e materiais na instituição, bem como de um protocolo, dificulta a rotina de checagem do CE, tarefa atribuída ao enfermeiro. 


\section{ABSTRACT}

It is a descriptive, exploratory and quantitative study that evaluates, by the standards of the Brazilian Society of Cardiology (SBC), the availability of the items of the Level I Emergency Cars (EC) of the largest emergency hospital in Rio Grande do Norte. Data were collected during the month of November 2010, the sample consists of 12 EC. All EC analyzed showed gaps in availability of essential items, being the greatest deficiencies related to materials intended for vascular access, circulation control and drugs aimed at treating the causes of cardiac arrest. It was felt institution, as well as a protocol, difficult routine check of the $\mathrm{EC}$, the nurse assigned task.

\section{INTRODUCCIÓN}

La parada cardiorrespiratoria (PCR), considerada como el cese súbito de la función cardiaca y de la respiración ${ }^{1}$, está entre las principales ocurrencias que exige atención de emergencia, realizada por un equipo debidamente capacitado y por la disponibilidad de los materiales y equipamiento necesarios para el soporte básico y avanzado de vida ${ }^{2-3}$.

Las drogas y equipamientos utilizados para la reversión de la PCR se hallan en el Carro de Emergencia (CE), que funciona como un armario y cuya estandarización es propuesta por la Sociedad Brasileña de Cardiología (SBC) basándose en las normas de la American Heart Association (AHA) ${ }^{2}$.

EI CE almacena materiales destinados a la evaluación y diagnóstico de la PCR, control de vias aéreas, acceso vascular, control circulatorio y medicamentos. Para su organización se considera como sector de permanencia para el CE el Centro Quirúrgico (CQ), las Unidades de Ingreso (UI), las Unidades de Terapia Intensiva (UTI) o el Pronto Socorro (PS) y se incluye la edad de la víctima (adulto o niño) y la demanda de PCR en el lugar ${ }^{4-5}$.

La disponibilidad del contenido del CE se basa en tres niveles de prioridad: los artículos de nivel I, que son considerados como esenciales, pues deben estar disponibles en el momento inmediato a la PCR; los de nivel II, que son altamente recomendados y que deben estar disponibles en un máximo de quince minutos; los artículos clasificados como de nivel III son recomendados, mas de disponibilidad opcional ${ }^{2}$.

Entre los artículos de nivel I están: desfibrilador externo automático, equipos de protección individual (EPI), cánula orofaríngea, bolsa válvula-máscarilla con reservorio de oxígeno, tubo endotraqueal, cánula para traqueotomía, laringoscopio (con lámina curva, para adulto, y recta, para niño), cánula nasal tipo gafas, cánula de aspiración flexible, jelco, aguja de intracath, equipo, frasco de vacío, gasa, microporo, aguja, suero fisiológico $(1000 \mathrm{ml})$, lactato de Ringer $(1000 \mathrm{ml})$ y suero glucosado $5 \%$ (500 $\mathrm{ml}$ ). También hay medicamentos esenciales, como agua destilada $(10 \mathrm{ml}, 250 \mathrm{ml}, 500$ $\mathrm{ml}$ ), aspirina, atropina, adrenalina, amiodarona, lidocaína, adenosina, $\beta$-bloqueador, nitroprusiato, nitroglicerina, cloruro de calcio, gluconato de calcio, sulfato de magnesio, procainamida, bicarbonato de sodio, glucosae $50 \%$, furosemida y broncodilatador ${ }^{2}$.

La organización y reposición de los materiales de los CE son responsabilidad del enfermero, pues este profesional tiene las atribuciones de realizar la asistencia directa al paciente y la administración de recursos humanos y materiales. Por tanto, el 
enfermero debe comprobar diariamente, hacer reposición de materiales y estar atento a la adecuación del $\mathrm{CE}^{2,6}$.

A partir de la vivencia en la graduación de Enfermería en el transcurso del período de prácticas supervisadas, en el mayor hospital público de urgencia de Rio Grande do Norte, fue posible percibir que el déficit de recursos materiales comúnmente lleva al equipo de la institución a utilizar los artículos del CE para la realización de procedimientos de rutina, que no se consideran como emergencia.

Se realizó así la presente investigación con el objetivo de evaluar los artículos de nivel I, considerados como esenciales, que están disponibles en los CE de los sectores CQ, UTI, UI y PS del hospital arriba citado. La relevancia de este estudio se encuentra en el hecho de que el CE es un elemento fundamental para la marcha atrás de las PCR, habiendo todavía lagunas en la literatura acerca de su organización y disponibilidad de sus artículos.

\section{METODOLOGÍA}

Estudio descriptivo y exploratorio, a fin de evaluar la disponibilidad de los artículos de nivel I de los CE de los sectores UI, UTI, CQ y PS del complejo formado por el Hospital Monsenhor Walfredo Gurgel y Pronto Socorro Clóvis Sarinho (HMWG/PSCS), mayor hospital de referencia en la atención de urgencia del Sistema Único de Salud en Rio Grande do Norte. El HMWG tiene capacidad para 264 camas fijas y la atención corresponde a una media de 21000 pacientes, de los cuales 1100 son ingresados. El PSCS posee capacidad para 62 camas fijas y recibe aproximadamente 13 mil pacientes por mes.

Tras el envío de una carta de anuencia a la dirección del hospital, solicitando autorización para la realización del estudio, se realizo la colecta de datos en el mes de noviembre de 2010, utilizando un instrumento adaptado del formulario para evaluación de los CE, propuesto por la SBC. Tras la colecta, los datos fueron analizados a través de estadística descriptiva simple, presentados en tablas a través de la frecuencia en porcentajes obtenidos.

Este trabajo no necesitó de la apreciación del Comitê de Ética en Investigación, por no involucrar en ninguna etapa a seres humanos o informaciones referentes a estos. La población de estudio estuvo compuesta por los CE disponibles para uso en los sectores arriba citados, estando la muestra compuesta por $12 \mathrm{CE}$.

\section{RESULTADOS}

Se encontraron $14 \mathrm{CE}$, de los que 12 estaban disponibles para la atención de las emergencias de los siguientes sectores: UTI general, UTI adulto, UTI pediátrica, dos UTI cardiológicas, cinco UI, sector unitrauma, reanimación y dos sectores de observación. No fue posible evaluar los CE del CQ debido a la falta de disponibilidad de ropa quirúrgica, exigida para entrar en el sector, y a la gran demanda de cirugías realizadas en la institución. En los sectores de Observación 1 y 2, que forman parte del PSCS, no había CE, teniendo que hacerse el desplazamiento del equipo de Reanimación, sector de localización más próximo.

Ninguno de los CE presentó todos los materiales considerados como de prioridad I, preconizados por la SBC. Los datos agrupados en las tablas 01 y 02 evidencian los 
resultados. De los CE analizados, ninguno presentó jelco y aguja de todos los calibres recomendados, ni todos los equipos de protección individual, estando las gafas presentes en solo uno de ellos; poco más de $50 \%$ tenían jeringas de todos los volúmenes y una minoría de CE presentó todos los tamaños de tubo endotraqueal y de cánula de aspiración.

Se tuvo en cuenta en el estudio la Solución Fisiológica, Solución Lactato de Ringer y Solución Glucosada de $500 \mathrm{ml}$, por ser estas las más empleadas en Brasil, estando todas ellas presentes en menos de la mitad de los CE.

Las mayores deficiencias se encontraron en las Unidades de Ingreso, cuyo problema más nítido es la falta de recursos materiales aliada con el elevado número de camas, que corresponde a una media de 37,6 camas por carro.

Solamente dos, de las cinco Ul evaluadas, tenían el Desfibrilador Externo Automático (DEA), otras dos tenían el cardioversor y una, el Centro de Tratamiento de Quemados, no tenía ninguno de estos equipos destinados a invertir la parada cardíaca. Ninguna de las UI tenía cánula nasal tipo gafas; aguja de intracath (para taponamiento y pneumotórax hipertensivo); nebulizador; microporo y bureta. En lo que se refiere a los medicamentos, ninguno de los CE de las unidades de ingreso tenía aspirina, $\beta$-bloqueador, procainamida y broncodilatador.

Entre los materiales que no se encontraron en ninguna de las UTI están: oxímetro de pulso, cânula nasal tipo gafas, conjunto de perfusión, frasco al vacío y bureta. En cuanto a los medicamentos, $100 \%$ de los carritos de las UTI no disponían de aspirina, clorato de cálcio, procainamida, broncodilatador y $\beta$-bloqueador. 
Tabla 01: Distribución de los artículos de nível I disponibles en los CE para la atención de pacientes adultos, HMWG/PSCS, Natal-RN. 2010.

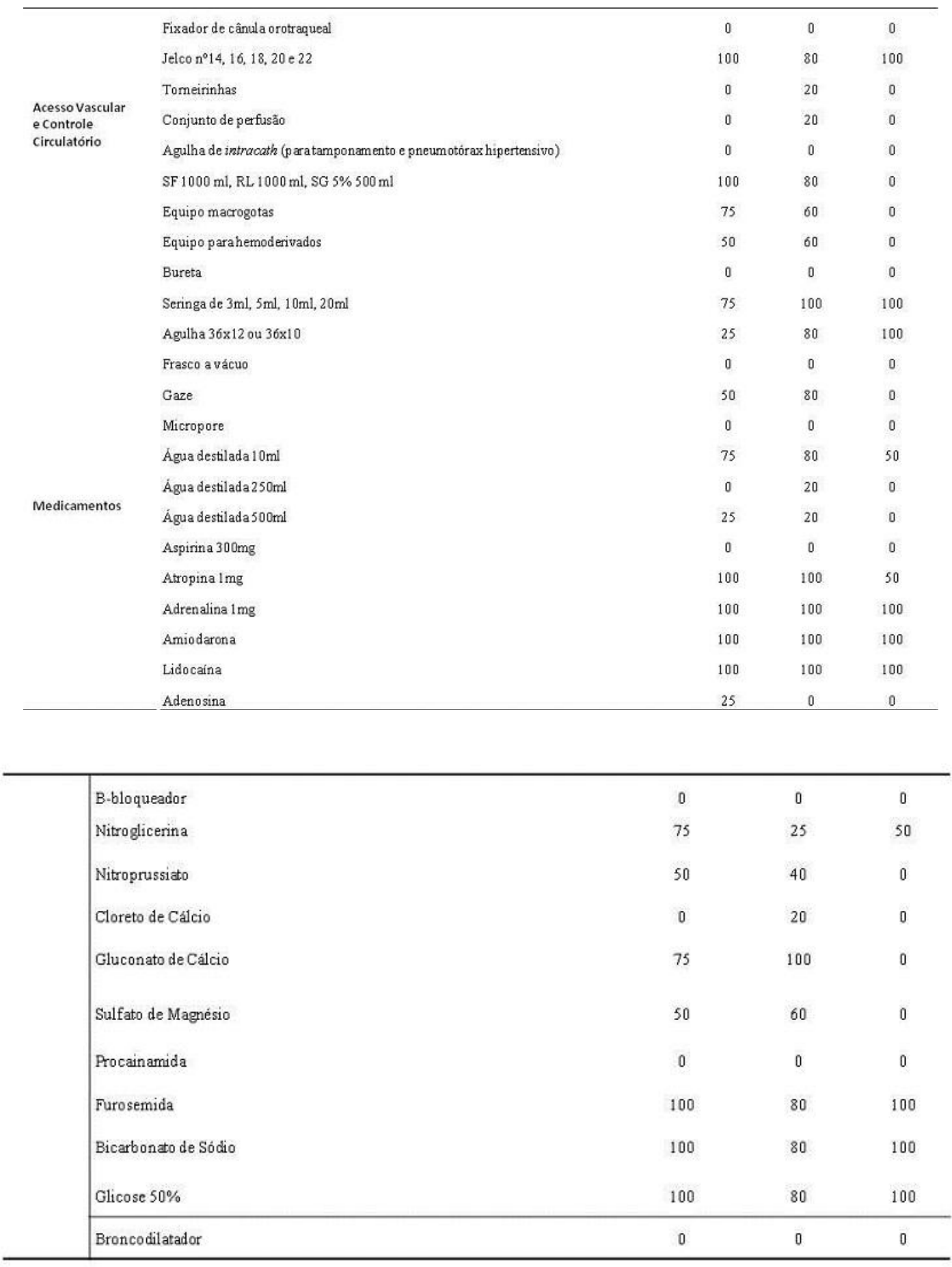

UTI=Unidade de Terapia Intensiva; UI=Unidade de Intemação; PS=Pronto Socorro; NA=Não se Aplica (materiais que não estão recomendados para o setor); $\mathrm{SF}=$ Solução Fisiológica, $\mathrm{RL}=$ Ringer Lactato, $\mathrm{SG}=$ Solução Glicosada

*Em um dos Carros de Emergência do Pronto Socorro, não foi possivel abrir uma das gavetas, pois a mesma estava travada devido ao excesso de materias.

** Em $40 \%$ dos CE das UI e em 50\% das UTI não estava disponivel o DEA ou o monitor/desfibrilador com marcapasso externo, mas estava presente 0 cardioversor.

***Dos EPI, foram encontrad os somente luvas e máscaras, o o cul os estava presente somente em um dos CE.

Fonte: Própria dapesquisa 
Tabla 02: Disponibilidad de los artículos de nível I para la atención en pediatría, HMWG/PSCS, Natal-RN, 2010.

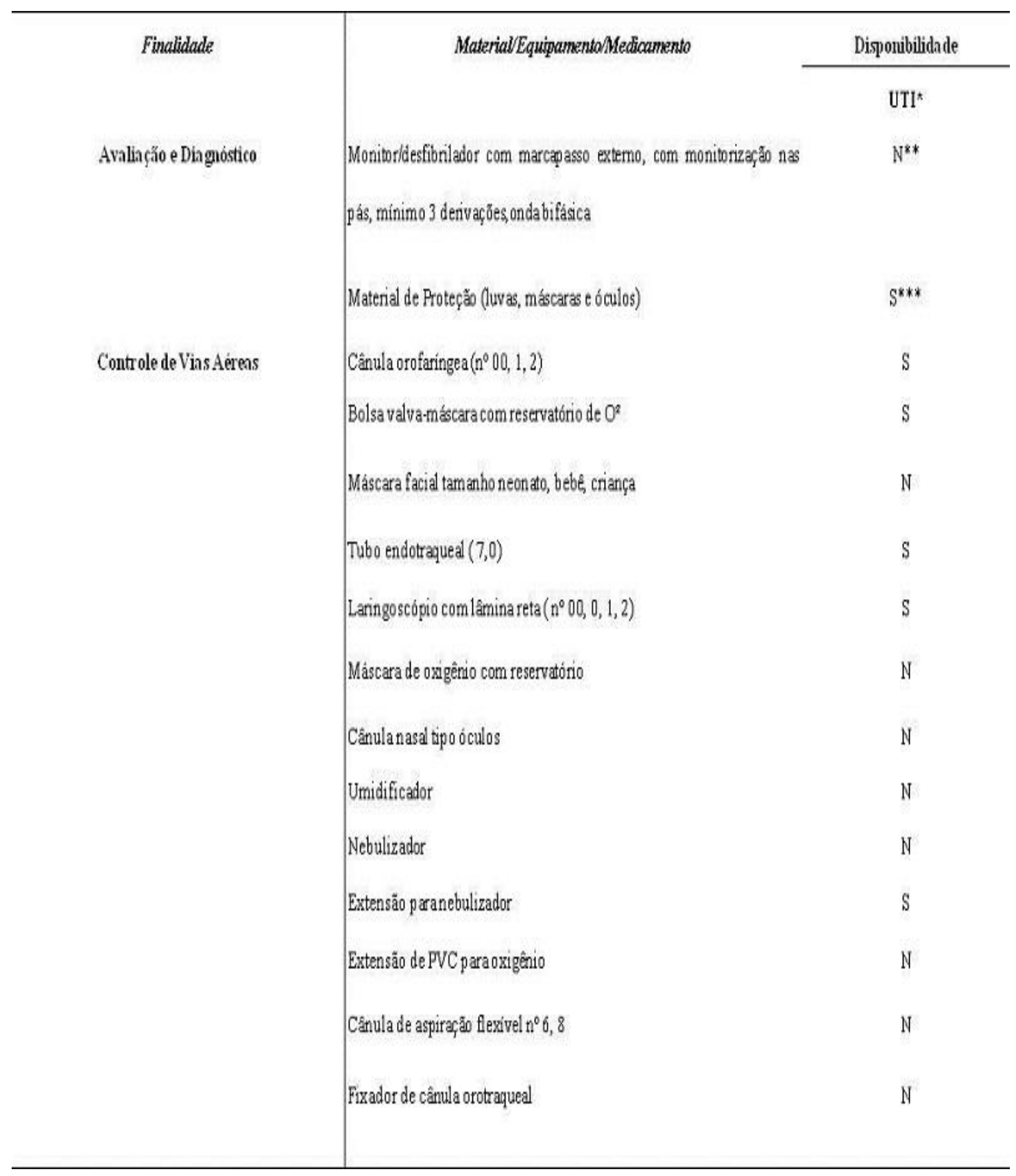




\begin{tabular}{|c|c|c|}
\hline \multirow[t]{13}{*}{ Acesso Vassular e C'ontrole Cirr culatorio } & Jelcon 022 e 24 & S \\
\hline & Agulha de punç̣ă intra-ossea & $\mathrm{N}$ \\
\hline & Tomeirinha & $\mathrm{N}$ \\
\hline & Conjunto de perfisăo & $\mathrm{N}$ \\
\hline & Agulha de intracath (para tamponamento e pneumotórax hipertensivo) & S \\
\hline & SF $1000 \mathrm{ml}, \mathrm{RL} 1000 \mathrm{ml}, \mathrm{SG} 5 \% 500 \mathrm{ml}$ & N \\
\hline & Equipo macrogotas & N \\
\hline & Equipo parahemodenvados & $\mathrm{N}$ \\
\hline & Bureta & $\mathrm{N}$ \\
\hline & Seninga de $3 \mathrm{ml}, 5 \mathrm{ml}, 10 \mathrm{ml}, 20 \mathrm{ml}$ & S \\
\hline & Agultha $36 \times 120436 \times 10$ & S \\
\hline & Frasco avácuo & $\mathrm{N}$ \\
\hline & Micropore & $\mathrm{N}$ \\
\hline \multirow[t]{5}{*}{ Medicamentos } & Águadestlada $10 \mathrm{ml}$ & S \\
\hline & Água destilada250ml & $\mathrm{N}$ \\
\hline & Ágra destilada $500 \mathrm{ml}$ & $\mathrm{N}$ \\
\hline & Asppirina $300 \mathrm{mg}$ & N \\
\hline & Atropina Img & s \\
\hline
\end{tabular}




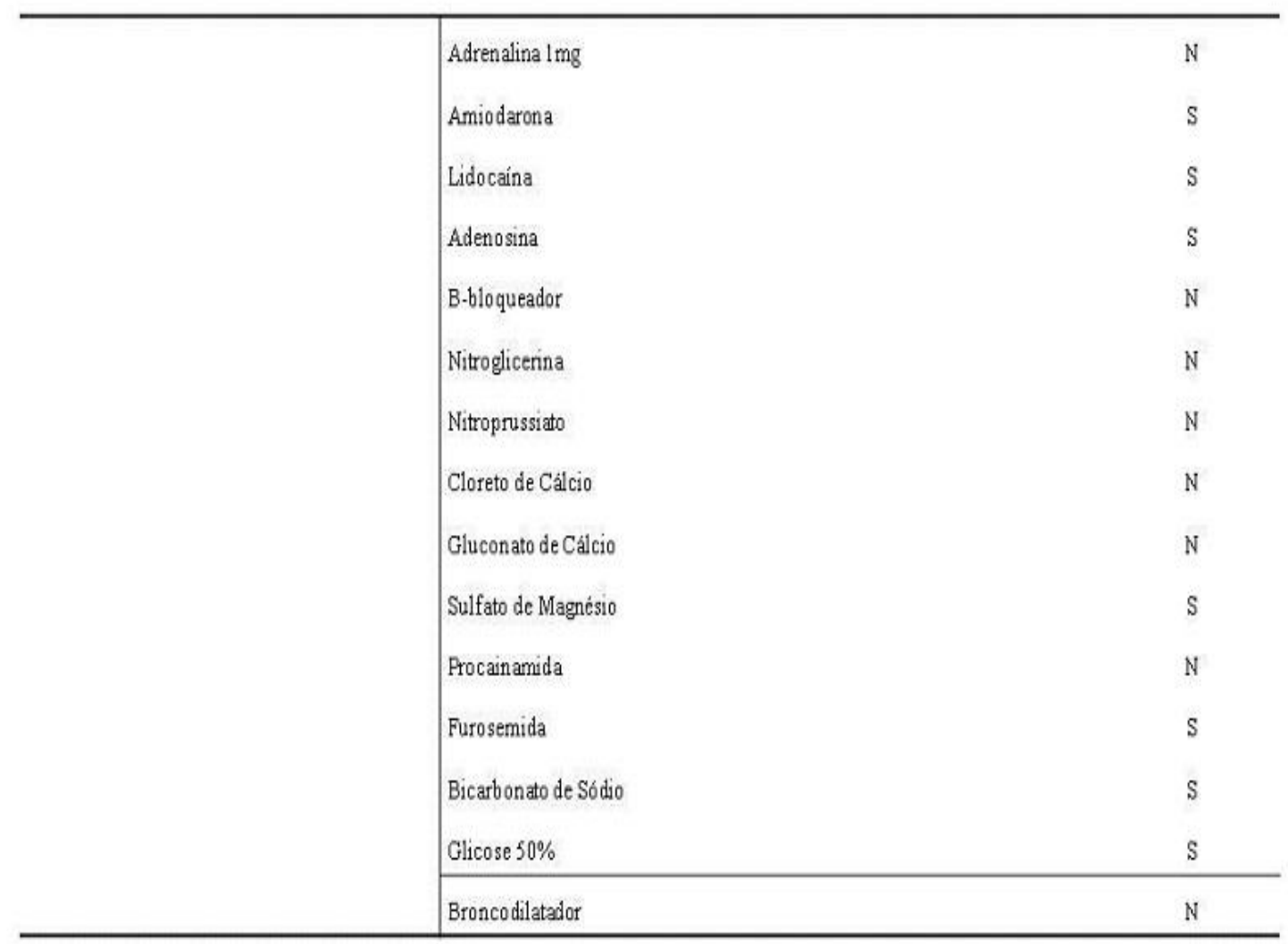

UTI=Unidade de Terapia Inten siva; $\mathrm{S}=\mathrm{Sim} ; \mathrm{N}=\mathrm{N}$ ăo.

*Alguns materiais estavam em falta devido ao uso do Carro de Emergência para o atendimento de uma Parada

Cardiorrespiratória pou cos minutos antes da análise

"No CE estava disponivel o Desfibrilador Externo Automático (DEA)

${ }^{* *}$ Dos EPI, estavam presentes somente luvas e máscaras

Fonte: Própria da pesquisa

\section{DISCUSIÓN}

Estudios señalan que el déficit de recursos humanos y materiales está entre las principales dificultades encontradas para la atención a la $\mathrm{PCR}^{7}$. En la presente investigación puede percibirse que $100 \%$ de los CE evaluados tenían deficiencias en la disponibilidad de materiales esenciales, resultados semejantes a los que se obtuvieron en estudio realizado en Pernambuco, en que todos los CE presentaron fallos, ${ }^{8}$ y en México, donde $90 \%$ de los CE presentaban deficiencias ${ }^{9}$.

En las situaciones de emergencia, debido a la dinámica de los procedimientos realizados, es de suma importancia que los profesionales utilicen todos los EPI para que estén menos expuestos a las fuentes químicas y biológicas de contaminación ${ }^{10}$. Por ello, lo que se ve en el presente estudio fue la deficiencia de los EPI, denotando mayor preocupación de los profesionales con la disponibilidad de medicaciones y materiales para acceso vascular y soporte ventilatorio, contraponiéndose a su protección contra fluidos biológicos.

En cuanto a los materiales de control de vías aéreas, la mayoría de los CE tenía todos los tamaños de tubo endotraqueal. Sin embargo, ninguno de los CE presentó cánula nasal tipo gafas y solo 16,66\% tenían todos los tamaños de cánula de aspiración. 
El manejo de las vías aéreas es una prioridad en situaciones en las que existe compromiso cardiocirculatorio, pues puede tener gran influencia en la eficacia de la recuperación y si es dificultada puede llevar a secuela permanente o muerte ${ }^{11}$.

De acuerdo con las tablas 01 y 02 , podemos ver que entre los CE analizados, ninguno tenía bureta, frasco al vacío y microporo, así como jelco y aguja de todos los calibres recomendados por la SBC y poco más de $80 \%$ tenían jeringas de todos los volúmenes.

En la atención a la PCR, muchas veces la administración de fármacos se considera como de segunda prioridad. Es de gran importancia la obtención de acceso vascular para administrar medicamentos y fluidos, en el intento de restablecer y mantener las condiciones de los latidos cardíacos y la circulación. De esta forma, la disponibilidad de los materiales para la instalación del acceso venoso, tales como jelcos, jeringas y agujas, debe ser respetada en los $C E$, ya que en las situaciones de emergencia se hace necesaria la infusión de grandes volúmenes y drogas, pues se está ante limitada reserva cardiocirculatoria, pulmonar y cerebral ${ }^{12}$.

En la mayoría de los CE estaban disponibles los medicamentos para la inversión de la PCR, tales como adrenalina, atropina, amiodarona y lidocaína, pero en ninguno de ellos estaban presentes los $\beta$-bloqueadores, broncodilatadores y procainamida. EI CE debe disponer no sólo de medicamentos utilizados en la inversión de la PCR, como también aquellos que se emplean em el tratamiento de las causas de parada cardíaca, tales como los síndromes coronarios agudos, la insuficiencia cardiaca congestiva y el edema agudo de pulmón ${ }^{2,8,13}$.

\section{CONCLUSIÓN}

A través de esta investigación, se percibió que ninguno de los CE analizados corresponde a los patrones propuestos por la SBC, teniendo la deficiencia de artículos imprescindibles para la atención inmediata a la PCR, probablemente debido a la falta de un protocolo de comprobación de los CE y de recursos materiales en el hospital aliados con la gran demanda de camas y el déficit de recursos humanos, lo que imposibilita una rutina de comprobación del $\mathrm{CE}$, tarea de responsabilidad del enfermero.

Es necesaria una mayor fiscalización de la organización, mantenimiento de los CE y la disponibilidad de sus materiales y que el equipo del hospital elabore un protocolo coincidente con su realidad y rutina, creando ayudas para una mejor asistencia a la PCR.

\section{REFERENCIAS}

1. Luzia MF, Lucena AF. Parada cardiorrespiratória do paciente adulto no âmbito intra-hospitalar: subsídios para a enfermagem. Rev. Gaúcha Enferm. 2009; 30(2):32837.

2. Sociedade Brasileira de Cardiologia (SBC). Diretriz de Apoio ao Suporte Avançado de Vida em Cardiologia - Código Azul - Registro de Ressuscitação - Normatização do Carro de Emergência. Arq. Bras. Cardiol. 2003; 81 Supl 4: 3-14.

3. Lima MADS, Pereira WAP. Atendimento pré-hospitalar: caracterização das ocorrências de acidente de trânsito. Acta Paul Enferm. 2006; 19(3):279-83. 
4. Portugal, Ministério da Saúde. Organização do material de emergência nos serviços e unidades de saúde. Direção Geral da Saúde. Orientação da Direção Geral da Saúde. Portugal: Ministério da Saúde; 2011.

5. Guimarães HP, Lopes RD, Lopes AC. Parada cardiorrespiratória. São Paulo: Atheneu; 2005.

6. Smeltzer CS, Bare GB. Brunner \& Suddarth-Tratado de Enfermagem MédicoCirúrgica. 9aㅡ ed. Rio de Janeiro: Guanabara Koogan; 2005.

7. Batista KM, Bianchi ERF. Estresse do enfermeiro em unidade de emergência. Rev. Lat. Am. Enferm. 2006; 4(14): 534-9.

8. Lima SG. Os carros de emergência e o suporte avançado de vida. Rev Bras Clin Med. 2010; 5(8):399-404.

9. Becerra CAR, Veja JS, Aguirre JMÓ. Evaluación de Conocimientos y Equipamiento en los Carros Rojos para la Reanimación Cardiopulmonar en una Unidad de Tercer Nivel de Atención. Medicrit junio. 2008; 2(5):63-73.

10. Batistoni EA, Barbosa D, Santos LHG, Andreazzi D. Importância do EPI: percepção da equipe de enfermagem na sala de emergência. Rev Eletr Acervo Saúde. [on line]. 2010 [citado 2011 fev 02] 2:[aprox.15 telas]. Disponível em: http://www.acervosaude.com.br/artigo 006 54.html.

11. Amantéa SL, Piva JP, Zanella MI, Bruno F, Garcia PCR. Acesso rápido à via aérea. Jornal de Pediatria. 2003; 79 Supl 2:127-138.

12. Sociedade de Cardiologia do Estado de São Paulo (SOCESP). Estabelecimento e manutenção das vias de infusão de medicamentos. Rev SOCESP [on line]. 2002 jun; [citado 2002 jun 25] [aprox.. 9 telas]. Disponível em: http://www.uff.br/mmi/disseccao\%20final\%20ead\%205/conteudo/punca0\%20e\%20dis secca01.pdf

13. Hardman JG, Limbird LE. Goodman \& Gilman - As bases farmacológicas da terapêutica. 10ª ed. Rio de Janeiro: McGraw-Hill; 2003.

ISSN 1695-6141

๑ COPYRIGHT Servicio de Publicaciones - Universidad de Murcia 